\title{
OGRANICZENIA MOŻLIWOŚCI KORZYSTANIA Z PRAW ZAGWARANTOWANYCH W MIĘDZYNARODOWYM PAKCIE PRAW GOSPODARCZYCH, SPOLECZNYCH I KULTURALNYCH NA PODSTAWIE JEGO ART. 4 A PROGRESYWNA REALIZACJA TYCH PRAW*
}

Złożoność życia publicznego oraz wzgląd na prawa i wolności innych wymagają od każdego podmiotu uprawnionego poddania się pewnym ograniczeniom w korzystaniu z przysługujących mu praw i wolności. W różnych aktach prawnych gwarantujących te prawa przepisy regulujące kryteria dopuszczalności wprowadzania ograniczeń przybierają różną formę. W Międzynarodowym pakcie praw gospodarczych, społecznych (socjalnych) ${ }^{1}$ i kulturalnych ${ }^{2}$ (dalej: MPPGSK albo Pakt) zdecydowano się zawrzeć - w art. 4 - ogólną klauzulę limitacyjna zawierającą rozbudowany katalog kryteriów dopuszczalności wprowadzania ograniczeń (jak: wymóg oparcia ograniczeń na prawie, zakaz podważania istoty praw i wolności, uprawniony cel ograniczeń) ${ }^{3}$ i znajdująca zastosowanie do wszystkich zagwarantowanych w nim praw, nawet jeśli pewne przepisy szczegółowe, uzupełniające gwarancje poszczególnych praw czy wolności zawierałyby doprecyzowania co do dopuszczalnych ograniczeń w korzystaniu z nich ${ }^{4}$.

Fakt, że klauzula limitacyjna zawarta w Pakcie ma ogólny charakter, nie oznacza jednak, że musi znajdować ona zastosowanie do wszelkich sytuacji niemożliwości korzystania w pełni przez podmioty uprawnione z zagwarantowanych w nim praw. W niniejszym artykule uwaga skoncentrowana będzie na doniosłym problemie, jaki wyłania się na gruncie interpretacji Paktu i jego art. 4, którym to problemem jest precyzyjne rozumienie ograniczeń w korzystaniu z praw i wolności w nim zagwarantowanych w relacji do innych jego

\footnotetext{
* Artykuł został napisany w ramach projektu „Międzynarodowy Pakt Praw Gospodarczych, Społecznych i Kulturalnych - Komentarz”. Projekt został sfinansowany ze środków Narodowego Centrum Nauki przyznanych na podstawie decyzji numer DEC-2012/05/B/HS5/00544.

${ }^{1} \mathrm{~W}$ tekście tym świadomie używane jest pojęcie praw socjalnych, a nie społecznych, jako lepiej oddające istotę rzeczy niż termin użyty w Dzienniku Ustaw; por. np. Kędzia (2018): 2.

${ }^{2}$ Międzynarodowy pakt praw gospodarczych, społecznych i kulturalnych otwarty do podpisu w Nowym Jorku dnia 19 grudnia 1966 r., Dz. U. 1977, Nr 38, poz. 169.

${ }^{3}$ Szerzej na temat tego przepisu i wynikających z niego konsekwencji zob. Jóźwicki (2018) oraz Saul, Kinley, Mowbray (2014): 247-258.

${ }^{4}$ Por. np. Jóźwicki (2018): 189-191; Saul, Kinley, Mowbray (2014): 243-245.
} 
przepisów. Mam tu na myśli przede wszystkim art. 2 ust. 1 MPPGSK, który ustanawia zasadę progresywnej realizacji praw zagwarantowanych w Pakcie, a więc ich realizację w miarę możliwości (dostępnych zasobów) państwa. Zdaniem niektórych każda niepełna realizacja praw, również ta związana z niedostępnością zasobów, a szczególnie podejmowane przez państwa tzw. działania retrogresywne (obniżające poziom realizacji danego prawa ze względu na kurczące się zasoby), powinny być uznane za ograniczenia w rozumieniu art. 4 MPPGSK i tym samym zostać objęte zawartymi w nim kryteriami dopuszczalności ograniczeń ${ }^{5}$.

Aktywność Komitetu Praw Gospodarczych, Socjalnych i Kulturalnych (dalej: KPGSK albo Komitet) nie jest w tej materii ani rozbudowana, ani w pełni przejrzysta, ani też spójna. Pozwala jednak na pewne wnioski związane z delimitacja zakresów zastosowania art. 2 ust. 1 i art. 4 MPPGSK. W artykule podjęto próbę precyzyjnego rozgraniczenia kwestii związanych z niepełną możliwością korzystania przez podmioty uprawnione z praw zagwarantowanych w Pakcie wynikających z niedoboru zasobów (w zw. z art. 2 ust. 1) oraz tych, które wynikają z realizacji przez państwa innych uprawnionych celów (w zw. $\mathrm{z}$ art. 4). Podjęto więc próbę ukazania odmiennych konsekwencji, jakie wynikają z obu przepisów. Ukazanie odmiennej logiki, jaką się one rządzą będzie możliwe przede wszystkim na podstawie kryterium obowiązku poszanowania istoty praw i wolności zagwarantowanych w Pakcie, której bezwzględną nienaruszalność gwarantuje jego art. 4, podczas gdy w reżimie art. 2 ust. 1 nienaruszalność podobnego zakresu praw i wolności, który bywa określany mianem ich minimalnej treści (minimum core content), wydaje się w pewnym stopniu względna.

Travaux préparatoires pokazuja, że wyposażenie Paktu w ogólną klauzulę limitacyjną od początku budziło różne kontrowersje. Już na etapie prac nad Paktem pojawiały się nawet głosy, że art. 4 MPPGSK jest w istocie rzeczy zbędny, gdyż dotyczy on sytuacji, które objęte sa i tak zasadą progresywnej realizacji zagwarantowanych w nim praw i wolności. Z progresywną realizacja wiązano czasem uzasadnienie bardziej ogólnego brzmienia wielu sformułowań zawartych w art. 4. Możliwie ogólne sformułowanie tego przepisu miało być uzasadnione tym, że prawa gospodarcze, socjalne i kulturalne (dalej: PGSK) podlegają co do zasady progresywnej, a nie natychmiastowej realizacji, co inherentnie wiąże się z pewnym ich ograniczeniem czy, mówiąc precyzyjniej, niemożnością korzystania $\mathrm{z}$ nich $\mathrm{w}$ pełni przez podmioty uprawnione - zanim zostaną całkowicie zrealizowane. Warunki dopuszczalności ograniczeń korzystania z PGSK miałyby być określone na tyle szeroko i elastycznie, aby również ich niepełną realizację można było traktować jako ich ograniczenie w rozumieniu art. 4 MPPGSK 6 .

Ostatecznie przebieg prac przygotowawczych, co przyznają nawet zwolennicy tezy o stosowalności art. 4 MPPGSK do sytuacji niepełnej realizacji praw zagwarantowanych w Pakcie, a szczególnie do oceny wprowadzanych przez

\footnotetext{
5 Zob. Müller (2009) i podana tam literatura.

${ }^{6}$ Szerzej np. Saul, Kinley, Mowbray (2014): 246.
} 
państwa środków retrogresywnych ${ }^{7}$, pokazuje jednak, że art. 4 nie był pomyślany jako mechanizm do oceny tego rodzaju deficytów. Te miały być objęte art. 2 ust. 1 MPPGSK. Jest to wyraźnie widoczne chociażby w wypowiedziach reprezentanta Wielkiej Brytanii, który wyraźnie podkreślał, że art. 32 (aktualnie 4) rozwiąuje problem ograniczeń w korzystaniu z praw i wolności objętych Paktem, który nie został rozwiązany przez art. 1 (aktualnie 2 ) $^{8}$, a także w podobnych stanowiskach innych delegatów podczas dyskusji poprzedzającej wprowadzanie klauzuli limitacyjnej do Paktu9 .

Podejścia łączące art. $4 \mathrm{z}$ art. 2 ust. 1 MPPGSK świadczą o niezrozumieniu pojęć, którymi posługuje się Pakt oraz niezrozumieniu relacji pomiędzy progresywna realizacją praw a dopuszczalnością wprowadzania ograniczeń w korzystaniu z praw i wolności zagwarantowanych w Pakcie ${ }^{10}$. Progresywna realizacja dotyczy zobowiązania państw stron do realizowania praw zagwarantowanych $\mathrm{w}$ Pakcie w najwyższym możliwym stopniu, w jakim tylko pozwalają im na to środki. Klauzule limitacyjne dotyczą natomiast uprawnień po stronie państw stron do ograniczania przez nie korzystania z praw i wolności zagwarantowanych w Pakcie przez podmioty uprawnione, ze względu na realizację konkurujących z tymi prawami uprawnionych celów, takich jak interesy publiczne ${ }^{11}$ lub prawa i wolności innych. Podstawą rozróżnienia, czy mamy do czynienia z sytuacją mieszczącą się w zakresie art. 2 ust. 1, czy art. 4 MPPGSK, jest więc przyczyna, dla której jednostki nie mogą w pełni korzystać z jakiegoś prawa czy wolności. Raz jest nią niedostępność środków, uniemożliwiajacca pełną jego realizację, a raz - decyzja o realizacji kosztem danego prawa innego uprawnionego celu, który koliduje z możliwościa pełnego z niego korzystania $^{12}$. Prowadzi to do różnych konsekwencji, sprowadzających się do

${ }^{7}$ Müller (2009): 585-591; por. Alston, Quinn (1987): 194.

8 Summary Record of the 308th meeting of the UN Commission on Human Rights, 6 June 1952, E/CN.4/SR.308): 5-6.

${ }^{9} \mathrm{~Np}$. wypowiedzi: reprezentanta Australii (Summary Record of the 308th meeting: 5), reprezentanta Chile (Summary Record of the 308th meeting: 6); reprezentanta ZSRR (Summary Records of the 306th meeting of the UN Commission on Human Rights, 6 June1952, E/CN.4/ SR.306: 11); reprezentanta Francji (Summary Record of the 307th meeting of the UN Commission on Human Rights, 6 June 1952, E/CN.4/SR.307): 5); czy reprezentanta Pakistanu (Summary Record of the 308th meeting: 13).

${ }^{10}$ Por. Saul, Kinley, Mowbray (2014): 246-247.

${ }_{11}$ Np. przeprowadzanie projektów rozwojowych, budowa infrastruktury publicznej, ochrona bezpieczeństwa czy zdrowia publicznego itp.; por. Saul, Kinley, Mowbray (2014): 251-252.

${ }^{12}$ Należy przyznać, że może być to czasem trudne do rozgraniczenia, szczególnie gdy realizowanym uprawnionym celem będą prawa i wolności innych, które również należą do katalogu PGSK. Nie można wykluczyć, że pewne środki retrogresywne, nawet jeśli będą wynikały przede wszystkim z konieczności zmiany sposobu alokacji środków dla realizacji innych praw i wolności zagwarantowanych w Pakcie, będą stanowić działania, które będzie można scharakteryzować jako limitacje na gruncie art. 4 MPPGSK. Objęcie takich działań kryteriami dopuszczalności z art. 4 MPPGSK mogłoby mieć znaczenie dla wzmocnienia ochrony praw jednostki. Jak się jednak wydaje, wtedy działania państw podpadałyby zarówno pod art. 2 ust. 1 MPPGSK i wynikające z niego konsekwencje, jak i pod art. 4 MPPGSK i wynikające z niego konsekwencje. Lista wymogów, które musiałyby w takiej sytuacji spełnić, zawierałaby więc zarówno wymogi z katalogu kryteriów wynikajacych z art. 2 ust. 1, jak i z art. 4 MPPGSK. Nie oznaczałoby to jednak, że art. 2 ust. 1 i 4 MPPGSK pokrywają się ze soba, a jedynie, że działania państw spełniają zarówno znamiona 
różnego ukształtowania zobowiązań po stronie państw zgodnie z art. 2 ust. 1 albo art. 4 MPPGSK.

Konsekwencje dla państw w zakresie kształtowania sytuacji podmiotów uprawnionych na podstawie obydwu tych przepisów łączą pewne podobieństwa. Najważniejszym z nich jest to, że co do zasady ani limitacje, ani progresywny charakter realizacji PGSK nie moga prowadzić do naruszenia istoty (nature) czy minimalnej treści (minimum core content) praw i wolności ${ }^{13}$. Pojęcie istoty/ natury praw jest niezwykle trudne do abstrakcyjnego zdefiniowania. Brak w dotychczasowej aktywności Komitetu jednoznacznego stanowiska w tej materii. Można jednak przyjaćc, że nawet jeśli pojęcie natury (występujące w anglojęzycznej wersji Paktu) jest pojęciem szerszym niż pojęcie istoty (użyte w wersji polskiej), to jednak ta ostatnia - rozumiana zgodnie z utarta na gruncie prawa praw człowieka (w tym przyjętą w polskim porządku konstytucyjnym, a opartą na niemieckiej koncepcji Wesengehalt praktyka ${ }^{14}$ ) - nawet jeśli nie jest ekwiwalentem, to przynajmniej jest elementem natury. Koncepcja istoty opiera się „na założeniu, że każda wolność bądź prawo posiada pewien podstawowy czy minimalny zakres treściowy, którego usunięcie zniweczy faktyczne jej istnienie. Innymi słowy, ograniczenia wolności i praw nie moga prowadzić do całkowitego wydrążenia ich z rzeczywistej treści i pozostawienia tylko pozoru ich obowiąywania"15.

$\mathrm{Na}$ istotę każdego prawa czy wolności zagwarantowanego w Pakcie składają się te ich elementy, które są kluczowe z punktu widzenia realizacji podstawowych wartości, których wyrazem jest konkretne prawo czy wolność. Pozostałe zaś elementy stanowią elementy uboczne czy peryferyjne (peripheral elements). Te ostatnie są konieczne dla pełnej realizacji prawa, ale brak ich realizacji nie prowadzi do podważenia wartości, której wyrazem jest konkretne PGSK, a więc jego istoty („twardego jądra”) ${ }^{16}$. Elementy uboczne danego prawa można scharakteryzować jako derywaty albo dalsze konsekwencje istoty („otoczka”) ${ }^{17}$. Takie rozumienie obowiązku poszanowania natury praw zagwarantowanych w Pakcie, skutkujace obowiązkiem poszanowania przez państwa wprowadzające ograniczenia istoty praw i wolności, rozumianej jako ich pewna minimalna treść (czy używając języka znanego z orzecznictwa polskiego TK, „twarde jądro"18) dobrze oddaje intencję autorów Paktu. Została ona wyrażona przez przedstawiciela Chile składającego propozycję zawarcia w art. 4 tego wymogu. Podkreślał on, że obowiązek poszanowania istoty/ natu-

działań objętych art. 2 ust. 1, jak i art. 4 MPPGSK. Przyjęcie przez Komitet takiego kierunku musiałoby się wiązać jednak z bardzo precyzyjnym zdefiniowaniem pojęcia środków retrogresywnych i wyróżnieniem różnych ich rodzajów. Obecnie brak jednak precyzyjnej definicji tego pojęcia, co stanowi istotną trudność w ocenie tego rodzaju środków, nawet jedynie na gruncie art. 2 ust. 1, a co dopiero na gruncie art. 4 MPPGSK; por. np. Nolan (2014): 376.

${ }_{13}$ Por. Saul, Kinley, Mowbray (2014): 247.

${ }^{14}$ Szerzej np. Garlicki (2001); Garlicki, Wojtyczek (2016).

${ }^{15}$ Garlicki, Wojtyczek (2016): 96.

${ }_{16}$ Por. np. Coomans (2002): 244.

17 Por. np. Coomans (2004): 77.

18 Np. wyroki TK: z 12 stycznia 1999 r., P 2/98; z 25 maja 1999 r., Sk 9/98; z 10 kwietnia 2002 r., K 26/00; z 17 maja 2006 r., K 33/05. 
ry ma zapewnić, że żadne działania stanowiące ograniczenia nie będą mogły prowadzić do unieważnienia żadnego z praw $^{19}$.

Na gruncie niektórych z zagwarantowanych w Pakcie praw KPGSK dokonał pewnych ustaleń dotyczących ich minimalnej treści (minimum core content), która podlega natychmiastowej realizacji, co mieści się w minimalnym zakresie obowiązków państw (minimum core obligations) ${ }^{20}$. Może być to pomocne przy określaniu zakresu praw i wolności składających się na ich istotę na potrzeby art. 4 MPPGSK. Minimum core nie można jednak uznać za w pełni ekwiwalentne do istoty ${ }^{21}$. Koncepcję tę można co najwyżej w ograniczonym stopniu stosować na potrzeby rekonstrukcji pojęcia istoty z art. 4 MPPGSK. To, że koncepcja minimum core stosowana na gruncie art. 2 ust. 1 MPPGSK nie może służyć jako prosta analogia do rekonstrukcji pojęcia istoty w rozumieniu art. 4 MPPGSK, najdobitniej ukazuje względność tej pierwszej, a więc to, że realizacja tego, co uznane zostanie za minimalną treść praw, nie wiąze państw bez względu na żadne okoliczności.

Jak wynika to z logiki art. 2 ust. 1 MPPGSK i co potwierdził Komitet, niezrealizowanie minimalnej treści może być usprawiedliwione, gdy państwo dołożyło wszelkich starań w zakresie swoich możliwości, w tym tych związanych z międzynarodową współpracą i wsparciem ${ }^{22}$. Może więc w skrajnym przypadku przejawiać się w nierealizowaniu przez nie nawet minimalnej treści prawa, w tym tej składającej się na jego istotę (jeśliby uznać, że istota sprowadza się do zawężonego katalogu elementów składających się na dane prawo względem jego minimalnej treści - core content). Co więcej, minimalne obowiązki państw nie zawsze są rekonstruowane w odniesieniu do minimalnej treści praw. Czasem Komitet przychyla się do takiej interpretacji minimalnych zobowiąań państw do realizacji praw zagwarantowanych w Pakcie (co w art. 14 MPPGSK wyrażone zostało expressis verbis odnośnie do prawa do edukacji), która sprowadza się jedynie do obowiązku opracowania planu działania zmierzajacego do realizacji jakiegoś prawa ${ }^{23}$. Opracowanie takiego planu w żaden sposób nie może być uznane za realizację jakiegokolwiek elementu tego prawa, a tym bardziej składających się na nie elementów jego istoty („twardego jądra”). Jest natomiast bez watpienia krokiem ku realizacji tego prawa, który w sytuacjach

19 Summary Record of the 235th meeting of the UN Commission on Human Rights, 2 June 1951, E/CN.4/SR.235: 13.

${ }^{20}$ Np.: Komentarz Ogólny nr 4 z 1992 r., E/1992/23: pkt 8; Komentarz Ogólny nr 13 z 1999 r., E/C.12/1999/10: pkt 57; Komentarz Ogólny nr 14 z 2000 r., E/C.12/2000/4: pkt 43 i 44; Komentarz Ogólny nr 15 z 2003 r., E/C.12/2002/11: pkt 37 i 38; Komentarz Ogólny nr 17 z 2006 r. E/C.12/ GC/17: pkt 39 i 40; Komentarz Ogólny nr 18 z 2006 r., E/C.12/GC/18: pkt 31; Komentarz Ogólny nr 19 z 2008 r., E/C.12/GC/19: pkt 59.

${ }^{21}$ Koncepcja ta zresztą jest przedmiotem krytyki doktryny jako niespójna i rozbieżnie stosowana przez Komitet. Prowadzi to czasem nawet do formułowania postulatów zmierzających do jej porzucenia jako nieprzydatnej a nawet szkodliwej dla ochrony praw człowieka; Young (2008): 126-140.

22 An evaluation of the obligation to take steps to the "maximum of available resources" under an Optional Protocol to the Covenant. Statement, E/C.12/2007/1 z 21 September 2007: pkt 4 i 5; por. też: Komentarz Ogólny nr 3 z 1991 r., E/1991/23: pkt 10; por. także np. Komentarz Ogólny nr 19: pkt 60.

${ }^{23}$ Na gruncie prawa do edukacji zob. Komentarz Ogólny nr 11 z 1999 r., E/C.12/1999/4: pkt 9. 
skrajnego niedoboru zasobów może być uznany za wypełnienie minimalnych obowiązków państwa.

Czym innym jest natomiast wprowadzanie ograniczeń w korzystaniu z praw i wolności ze względu na różne uprawnione cele na podstawie art. 4 MPPGSK. W takiej sytuacji naruszenie istoty praw jest wykluczone. Wymóg ten jest bezwzględny, a koncepcję ochrony istoty należy uznać za absolutna, a nie relatywna. Jest to powszechnie przyjęta zasada na gruncie prawa praw człowieka. Należy zgodzić się z Andrzejem Wróblem, który w kategoriach ogólnych konkludował swe rozważania w tej materii na gruncie Karty praw podstawowych ${ }^{24}$, że: „przyjęcie koncepcji relatywnej utożsamiałoby ją z zasadą proporcjonalności. Według koncepcji absolutnej, istota każdej wolności i prawa ma charakter niezmienny, niezależnie od kontekstu regulacji ograniczającej[25] [...]. Zasadnicza różnica między koncepcją absolutną i koncepcją relatywną jest taka, że według koncepcji absolutnej istota prawa i wolności jest wyznaczona sztywna, abstrakcyjną granica, poza którą nigdy i w żadnych okolicznościach wykraczać nie wolno, gdy tymczasem teoria relatywna wyznacza granice zmienne w zależności od kontekstu, w jakim regulacja ograniczajacca jest badana" ${ }^{26}$.

Korzystanie z praw i wolności zagwarantowanych w MPPGSK może być ograniczone na podstawie art. 4 MPPGSK dopiero na takim etapie ich realizacji, który wykracza poza minimalną treść danego prawa. Artykuł 4 może więc znaleźć zastosowanie tylko wtedy i w takim zakresie, w jakim ograniczane prawo zostało zrealizowane ${ }^{27}$. Jak ujął to Fons Coomans: „rdzeń (core) prawa należy rozumieć [...] jako podstawę, od której państwa powinny wychodzić w swoich staraniach ku osiaganiu coraz wyższych poziomów realizacji”28. Jest ona w pewnym sensie punktem wyjścia progresywnej realizacji. Z drugiej zaś strony jest granica nie do przekroczenia podczas wprowadzania ograniczeń. Jeśli jednak obiektywnie brak środków na realizację danego prawa na poziomie obejmujacym ten punkt wyjścia, to nie można oczekiwać od państwa jego zrealizowania. Można sobie nawet wyobrazić, że w skrajnych przypadkach pogorszenia się dostępności zasobów poziom realizacji jakiegoś prawa czy wolności mógłby spaść (w ramach wprowadzenia tzw. środków retrogresywnych) poniżej realizowanej wcześniej minimalnej treści prawa ${ }^{29}$. Przecież impossibilium nulla est obligatio. Jeśli jednak ten minimalny poziom realizacji danego prawa jest osiagnięty, to wszelkie ograniczenia w korzystaniu z tego prawa, oparte na art. 4 MPPGSK, a więc zmierzające do realizacji innych uprawnionych celów, nie mogą go naruszać. To najdobitniej ukazuje różnicę pomiędzy logika, jaką rządzą się art. 2 ust. 1 i art. 4 MPPGSK.

W literaturze obecne sa jednak głosy postulujace obejmowanie art. 4 MPPGSK sytuacji podlegających art. 2 ust. 1, szczególnie wprowadzania przez państwa

${ }^{24}$ Karta praw podstawowych Unii Europejskiej, Dz. Urz. UE C 326 z 26 października 2012 r.

${ }^{25}$ Por. np. Garlicki (2001): 24.

${ }^{26}$ Wróbel (2013): 1352; tak samo: Garlicki, Wojtyczek (2016): 100; Wojtyczek (1999): 208.

${ }^{27}$ Por. Beiter (2006): 454.

${ }^{28}$ Coomans (2004): 78.

${ }^{29}$ Chociaż z drugiej strony Komitet wielokrotnie podkreślał, że środki retrogresywne naruszające minimalny zakres obowiązków stanowią naruszenie Paktu i zagwarantowanych w nim praw - zob. np. Komentarz Ogólny nr 14: pkt 48; por. Müller (2009): 588. 
środków retrogresywnych ${ }^{30}$. Artykuł 4 MPPGSK miałby być jednolitym narzędziem oceny wszelkiego rodzaju deficytów w możliwości korzystania przez podmioty uprawnione z praw i wolności zagwarantowanych w Pakcie. Głównym argumentem zwolenników tej tezy jest przekonanie, jakoby skutkować miało to wzmocnieniem ochrony tych praw ${ }^{31}$. Miałoby to uniemożliwiać państwom obchodzenie kryteriów z art. 4 przy wprowadzaniu de facto ograniczeń (jako środków retrogresywnych opartych na art. 2 ust. 1), niebędących ograniczeniami de iure (w rozumieniu art. 4$)^{32}$.

Stanowisko takie nie wydaje się jednak uzasadnione również w świetle aktywności KPGSK. Dość konsekwentnie zamierzoną retrogresję analizuje on w kategoriach obowiązków państw, a więc na gruncie art. 2 ust. 1, a nie w kategoriach limitacji, a więc bez żadnych odwołań do art. 4 art. 4 MPPGSK $^{33}$. Co więcej, w aktywności Komitetu można dostrzec tendencję do budowania równoległej do kryteriów zawartych w art. 4 MPPGSK listy kryteriów dopuszczalności wprowadzania środków retrogresywnych.

Jak KPGSK podkreślił to już w Komentarzu ogólnym nr 3: „rozmyślne wprowadzanie środków retrogresywnych [...] wymaga szczególnie wnikliwego rozważenia i będzie musiało być w pełni uzasadnione w odniesieniu do ogółu praw zagwarantowanych w Pakcie, a także w kontekście obowiązku pełnego wykorzystania dostępnych zasobów"34. Komitet wskazał też już kryteria oceny działań państw powołujących się na ograniczone zasoby jako uzasadnienie zastosowania środków retrogresywnych. Są to: poziom rozwoju państwa; powaga przypuszczalnych naruszeń, a szczególnie to, czy sytuacja miałaby wpływ na minimalny zakres prawa (minimum core content); aktualna sytuacja ekonomiczna państwa (szczególnie okoliczność, czy państwo przechodziło w danym momencie okres recesji); występowanie innych poważnych roszczeń dotyczących ograniczonych zasobów państwa (np. wynikających z niedawnych katastrof naturalnych albo wewnętrznych lub międzynarodowych konfliktów zbrojnych); czy państwo próbowało znaleźć niskokosztowe rozwiązania alternatywne; czy państwo szukało współpracy i wsparcia; czy też bez wystarczających powodów odrzucało propozycje dotyczące możliwości skorzystania z zasobów wspólnoty międzynarodowej ${ }^{35}$.

Szczególnie ostatnie lata przyniosły ze sobą poważne wyzwania dla realizacji PGSK w związku z globalnym kryzysem ekonomicznym. Związane z nim szeroko wdrażane programy oszczędnościowe (austerity programmes) skłoniły Komitet do rozwinięcia i usystematyzowania swoistej doktryny kryzysowej (emergency doctrine) ${ }^{36}$. Przewodniczący Komitetu zwrócił się z listem do

${ }^{30}$ Np. Craven (1998): 132; por. Alston, Quinn (1987): 205-206; Beiter (2006): 457-458; Lekkie (1998): 99; Müller (2009): 569-585.

31 Müller (2009): 569-585.

32 Zob. Alston, Quinn (1987); Müller (2009): 590.

${ }^{33}$ Np. Komentarz Ogólny nr 13: pkt 45; Komentarz Ogólny nr 14: pkt 32, 48; Komentarz Ogólny nr 15: pkt 19, 42; Komentarz Ogólny nr 18: pkt 21, 34; Komentarz Ogólny nr 19: pkt 42, 64.

${ }^{34}$ Komentarz Ogólny nr 3: pkt 9; por. Komentarz Ogólny nr 13: pkt 45.

${ }^{35}$ KPGSK, An evaluation of the obligation: pkt 10.

${ }^{36}$ Kędzia (2014): 31. 
państw stron Paktu, w którym w obliczu konieczności wdrażania dotkliwych społecznie programów oszczędnościowych stwierdził, że „zgodnie z postanowieniami Paktu wszystkie państwa strony powinny zawsze unikać podejmowania decyzji, które mogłyby doprowadzić do zaprzeczenia albo naruszenia praw gospodarczych, socjalnych i kulturalnych" ${ }^{37}$. Podkreślił także znaczenie PGSK dla bezpieczeństwa społecznego i spokoju społecznego, a także szczególne znaczenie realizacji PGSK dla grup zmarginalizowanych i nieuprzywilejowanych (defaworyzowanych) społecznie. Przyznał również, że „kryzys ekonomiczny i finansowy oraz brak rozwoju, utrudniają progresywną realizację praw gospodarczych, socjalnych i kulturalnych i moga prowadzić do retrogresji w korzystaniu z tych praw"38.

Co więcej, przewodniczący podkreślił, że wszelkie dostosowania w realizacji praw, jakie mogą być w takich warunkach nieuniknione, muszą spełniać określone cztery warunki: muszą być tymczasowe i ograniczać się do czasu kryzysu; muszą być konieczne i proporcjonalne, w sytuacji gdy wprowadzenie innych programów albo brak działań byłby bardziej szkodliwy dla PGSK; nie mogą mieć charakteru dyskryminującego i muszą zawierać wszelkie możliwe środki, w tym podatkowe, ograniczające nierówności, które to mogłyby wzrastać w czasach kryzysu, a także powinny zapewniać, że grupy nieuprzywilejowane (defaworyzowane) i zmarginalizowane nie będą dotknięte takimi programami w sposób nieproporcjonalny; wreszcie muszą uwzględniać minimalną treść praw i zapewniać jej nieprzerwaną ochronę ${ }^{39}$.

Jak wyraźnie wynika z powyższych ustaleń, możliwość wprowadzania środków retrogresywnych Komitet wiąże z niedoborem zasobów. Konsekwentnie konstruuje także, równolegle do art. 4 MPPGSK, katalog kryteriów dopuszczalności wprowadzania środków retrogresywnych w ramach art. 2 ust. 1, które to kryteria jedynie w pewnym stopniu pokrywaja się z kryteriami zawartymi w art. 4 i uwzględniają odmienną logikę, jaką żądzą się oba przepisy. Pewne podobieństwa niektórych elementów, jakie Komitet zawarł w przedstawionych powyżej kryteriach oceny niepełnej realizacji praw zagwarantowanych w Pakcie i wprowadzania środków retrogresywnych do kryteriów dopuszczalności ograniczeń, zawartych $\mathrm{w}$ art. 4 sa naturalne. Nie wynikaja jednak z zastosowania art. 4, a jedynie z pewnych ogólnych zasad, na których opiera się cały Pakt, czy szerzej - międzynarodowe prawo praw człowieka, i które przenikają wiele jego postanowień, jak choćby zasada proporcjonalności i kryterium konieczności.

Artykuł 4 MPPGSK, w którym wiele konsekwencji tych zasad wyrażono, może służyć za źródło inspiracji przy wykładni niektórych konsekwencji wynikających z art. 2 ust. 1, szczególnie odnośnie do dopuszczalności wprowadzania środków retrogresywnych. Nie można go jednak w całości stosować do stanów podpadających pod art. 2 ust. 1, gdyż w dłuższej perspektywie mogłoby

${ }^{37}$ List Przewodniczacego KPGSK skierowany do państw stron MPPGSK z 16 maja 2012, CESCR/48 $\left.8^{\text {th }} / \mathrm{SP} / \mathrm{MAB} / \mathrm{SW}\right): 1$ (tłum. własne).

${ }^{38}$ List Przewodniczącego KPGSK: 2 (tłum. własne).

${ }^{39}$ List Przewodniczącego KPGSK: 2. 
to prowadzić do, wbrew temu co twierdzą niektórzy, osłabienia jego ochronnej roli dla praw zagwarantowanych w Pakcie. Mam tu na myśli przede wszystkim ewentualną relatywizację, a więc podważenie absolutnego charakteru obowiązku poszanowania istoty praw i wolności, jaki zawiera art. 4. Gdyby do tego doszło, np. podczas stosowania art. 4 do oceny działań retrogresywnych w sytuacji faktycznej, obiektywnej i niepodważalnej niemożności zrealizowania minimalnej treści danego prawa, skutkującej obniżeniem poziomu jego realizacji do stanu nieobejmującego elementów minimalnej treści tego prawa, składających się na jego istotę, Komitet musiałby to zaakceptować. Byłby to niezwykle niebezpieczny precedens, który państwa mogłyby próbować wykorzystywać, wprowadzając sensu stricto ograniczenia w korzystaniu z praw i wolności. Komitet powinien więc nie ustawać w rozwijaniu i doprecyzowywaniu kryteriów oceny stanów niepełnej realizacji PGSK, w tym kryteriów oceny dopuszczalności wprowadzania środków retrogresywnych w ramach stosowania art. 2 ust. 1 MPPGSK, inspirując się niektórymi kryteriami z art. 4, ale nie powinien „wypożyczać” go do tego celu. Takie stosowanie art. 4 byłoby sprzeczne z intencjami autorów Paktu, sprzeczne z dotychczasowa aktywnością Komitetu, a co gorsza, mogłoby osłabić ochronną funkcję art. 4 przez relatywizacje absolutnego na gruncie tego przepisu obowiązku poszanowania istoty praw objętych Paktem w sytuacjach wprowadzania przez państwa sensu stricto ograniczeń w korzystaniu z tych praw.

Procedura skargowa w ramach systemu MPPGSK umożliwi podmiotom uprawnionym do korzystania z praw i wolności zagwarantowanych w Pakcie dochodzenie ich w trybie indywidualnym przed Komitetem. Inne procedury, w tym szczególnie sprawozdania państw i procedura monitorowania wykonywania przez państwa postanowień Paktu, skupiają się raczej na perspektywie makroskopowej ${ }^{40}$. Procedura skargi indywidualnej będzie dotyczyć bezpośrednio konkretnych przypadków ograniczeń korzystania z konkretnych praw i wolności. Konkretne podmioty uprawnione będą mogły zgłaszać takie sytuacje, dając Komitetowi szansę ich oceny pod kątem art. 4 MPPGSK. Co jednak wydaje się ważne, to to, aby Komitet od samego początku zdawał sobie sprawę z różnic pomiędzy art. 2 ust. 1 a art. 4 MPPGSK, a także różnych rodzajów aktywności państw, które objęte są zakresem zastosowania obu tych przepisów, i wynikających z nich konsekwencji i właściwie je stosował w sprawach przed nim stającymi, doprecyzowując ich rozumienie, a nie rozmywając granicę pomiędzy nimi.

Aby mogło tak się stać, konieczne będzie również precyzyjne stosowanie Protokołu dodatkowego do MPPGSK (dalej: Protokół) ${ }^{41}$ ustanawiającego na jego gruncie procedurę skargi indywidualnej ${ }^{42}$, a szczególnie jego art. 8 ust. 4. Zgodnie z tym przepisem, badając zawiadomienia, Komitet oceniać będzie rozsądność (reasonableness) kroków podjętych przez państwo zgodnie z częścia II Paktu ${ }^{43}$. Wymóg rozsądności jest wymogiem rzadko spotykanym w innych,

\footnotetext{
40 Por. Saul, Kinley, Mowbray (2014): 247.

${ }^{41}$ Protokół fakultatywny do Międzynarodowego paktu praw gospodarczych, społecznych i kulturalnych, Rezolucja Zgromadzenia Ogólnego ONZ, A/RES/63/117 z 10 grudnia 2008.

42 Szerzej np. Hauser (2018): 818-819.

43 Szerzej np. Griffey (2011); Mahon (2008); Chenwi (2009).
} 
analogicznych protokołach do traktatów praw człowieka ${ }^{44}$. Wymóg ten nie jest jednak zupełnie bezprecedensowy. W dużej mierze został on ukształtowany na wzór systemu konstytucyjnego w Republice Południowej Afryki ${ }^{45}$. W podejściu do art. 8 ust. 4 Protokołu można dostrzec tendencję do tego, aby, nawiązując w tej materii do aktywności Trybunału Konstytucyjnego RPA, rozsądność podejmowanych przez państwa kroków traktować jako pojęcie o własnej treści normatywnej, a więc takie, na które składają się zawarte w nim kryteria oceny ${ }^{46}$.

Szczególnie drugie zdanie art. 8 ust. 4 Protokołu $^{47}$ wpisuje dość silnie interpretację tego pojęcia $\mathrm{w}$ logikę art. 2 ust. 1 MPPGSK. Wykładnia pojęcia rozsądności powiązana $\mathrm{z}$ art. 2 ust. 1 Paktu dominuje w aktualnej literaturze przedmiotu ${ }^{48}$, co potwierdzają również dokumenty organów $\mathrm{ONZ}^{49}$. Jak stwierdził to sam Komitet, będzie on oceniał skargi dotyczace niepowodzeń państw $\mathrm{w}$ realizacji praw zagwarantowanych w Pakcie do maksimum dostępnych im środków, sprawdzając, czy podejmowana przez państwa działania spełniały kryterium rozsądności i adekwatności, m.in. zgodnie z następującymi kryteriami: stopień, w jakim podjęte środki były zamierzone, konkretne i nacelowane na wypełnianie praw GSK; czy państwo skorzystało z przysługującego mu luzu decyzyjnego w sposób niedyskryminujący i niearbitralny; czy decyzja państwa, aby (nie) przydzielić dostępnych środków, była w zgodzie z międzynarodowymi standardami praw człowieka; czy w przypadku, gdy dostępnych jest kilka rozwiązań, państwo zastosowało taką politykę, która w najmniejszym stopniu ogranicza prawa chronione Paktem; przedział czasowy, w jakim zostały podjęte kroki, oraz to, czy wzięto pod uwagę niepewną sytuację jednostek i grup nieuprzywilejowanych i marginalizowanych; czy podjęte kroki były niedyskryminacyjne i czy nadawały priorytet sytuacjom poważnym albo szczególnie ryzykownym ${ }^{50}$.

Stanowiska tego nie należy jednak rozumieć jako wyczerpującego złożoność kwestii związanych z interpretacja i potencjalnym stosowaniem art. 8 ust. 4 MPPGSK i zawartego w nim kryterium rozsądności. Podejście ograniczające rozumienie kryterium rozsądności do wiązania go z przywołana powyżej wypowiedzią Komitetu byłoby kolejnym przejawem niebezpiecznego zacierania różnic pomiędzy art. 2 ust. 1 i art. 4, szczególnie jeśli pojęcie rozsądności miałoby być uznane za pojęcie autonomiczne, a składające się na nie kryteria miałyby mieć uniwersalny charakter. Przywoływane powyżej stanowisko Komitetu dotyczy art. 8 ust. 4 Protokołu i zawartego w nim kryterium

${ }_{44}$ Szerzej np. The Optional Protocol to the International Covenant on Economic, Social and Cultural Rights, Geneva Academy, Geneva 2013, <https://www.geneva-academy.ch/joomlatoolsfiles/docman-files/The\%20optional\%20protocol\%20In\%20brief\%202.pdf>: 25-26.

${ }^{45}$ Por. The Optional Protocol: 27-29.

${ }^{46}$ The Optional Protocol: $28 \mathrm{n}$.

${ }^{47}$ Stanowi ono, że: „Czyniąc to, Komitet weźmie pod uwagę, że Państwa-Strony mogą zastosować szeroki zakres potencjalnych środków majacych na celu implementację postanowień zawartych w Pakcie".

${ }^{48}$ Zob. np. The Optional Protocol: 25-29 oraz podana tam literatura.

${ }^{49}$ Draft Optional Protocol to the International Covenant on Economic, Social and Cultural Rights, Explanatory Memorandum, A/HRC/6/WG.4/2 of 23 April 2007: pkt 29.

${ }^{50}$ KPGSK, An evaluation of the obligation: pkt 8. 
rozsądności w kontekście art. 2 ust. 1 MPPGSK. Nie oznacza to jednak, że jest to wyczerpujące rozumienie tego wymogu i że w dalszej swej aktywności Komitet nie będzie mógł pojęcia tego dalej doprecyzowywać w związku z innymi przepisami Paktu, w tym z jego art. 4. Nota bene Komitet używał już, choć w nierozbudowany sposób, kryterium rozsądności również w kontekście innych przepisów części II Części Paktu, jak choćby art. 2 ust. $2^{51}$ czy interesującego nas art. $4^{52}$.

Kryterium rozsądności należy uznać za odnoszące się w takim samym stopniu do obowiązków państw wynikających z art. 2 ust. 1 MPPGSK, jak i jego art. $4^{53}$. Wydaje się, że dla precyzji stosowania Paktu, a co za tym idzie - i dla lepszej ochrony praw jednostki, najlepiej byłoby, aby zawarte w art. 8 ust. 4 Protokołu kryterium rozsądności traktować jako klauzulę generalna, niemająca samodzielnej treści, a odsyłającą do przepisów części ogólnej Paktu. Za spełniające kryterium rozsądności w rozumieniu art. 8 ust. 4 Protokołu należałoby więc uznawać takie zachowania państw, które spełniałyby odpowiednio wszystkie wymogi określone w części II Paktu, do której to art. 8 ust. 4 Protokołu expressis verbis odsyła, w zależności od tego, który z przepisów części II Paktu znajdowałby w danej sytuacji zastosowanie. Działania państw, opisane w zawiadomieniu, byłyby więc oceniane przez Komitet przez pryzmat ich rozsą dności w zakresie obowiązku realizacji praw i wolności do maksimum zasobów i stopniowego osiagnięcia pełnej realizacji praw zagwarantowanych w Pakcie, w tym ewentualnego wprowadzania w razie konieczności środków retrogresywnych (art. 2 ust. 1 MPPGSK), zakazu dyskryminacji (art. 2 ust. 2 i 3 MPPGSK), równości kobiet i mężczyzn (art. 3 Paktu), dopuszczalności wprowadzania ograniczeń w korzystaniu z praw i wolności ze względu na realizację innych uprawnionych celów (art. 4 MPPGSK), a także zakazu nadużywania postanowień Paktu (art. 5 ust. 1 MPPGSK) oraz obowiązku ochrony uznanych na podstawie innych źródeł praw i wolności człowieka, jeśli byłyby one korzystniejsze dla jednostki (art. 5 ust. 2 MPPGSK) wraz ze wszystkimi wynikajacymi stąd konsekwencjami. Wprowadzanie jednorodnego kryterium rozsąności (reasonableness) dla wszystkich tych, jakże odmiennych, kategorii zobowiązań państw jako mechanizmu oceny skarg składanych na podstawie Protokołu fakultatywnego do MPPGSK, prowadziłoby do zagubienia specyfiki każdego z tych przepisów i skutkowałoby niemożnością uwzględnienia specyfiki sytuacji, które im podlegaja, a co za tym idzie - do osłabienia ochrony praw jednostki, jaką Pakt ma zapewniać.

Podsumowując, należy więc stwierdzić, że zawarta w art. 4 MPPGSK klauzula limitacyjna jest specyficznym narzędziem, umożliwiającym państwom stronom Paktu wprowadzanie ograniczeń w korzystaniu przez podmioty do tego uprawnione z praw w nim zagwarantowanych. Stan możliwości niepeł-

${ }^{51}$ Np. Komentarz Ogólny nr 20 z 2009 r., E/C.12/GC/20: pkt 9, 13, 21, 27, 28, 31, 33; por. też np. Griffey (2011): 285-286.

${ }^{52}$ Np. Komentarz Ogólny nr 7 z 1997 r., E/1996/22, Annex IV: pkt 14; por też: Limburg Principles on the Implementation of the ICESCR, E/CN.4/1987/17 of 8 January 1987: pkt 49 (tłum. własne).

${ }^{53}$ Por. Courtis (2010): 82. 
nego korzystania z danego prawa czy wolności to jednak za mało, aby można było mówić o ograniczeniach sensu stricto w rozumieniu art. 4 MPPGSK. Te ostatnie muszą służyć realizacji innych uprawnionych celów, zmierzających do popierania powszechnego dobrobytu w społeczeństwie demokratycznym, a nie wynikać z niedoboru zasobów.

Stan niepełnego korzystania z praw i wolności może wynikać też z takich okoliczności, jak niepełna realizacja danego prawa czy wolności i stojący za nią brak zasobów. Tego rodzaju deficyty podlegają art. 2 ust. 1 MPPGSK. Oba te przepisy obejmują sytuacje w pewnym sensie podobne, inna jest jednak za każdym razem racja stojąca za niemożnością korzystania $\mathrm{w}$ pełni z danego prawa czy wolności, co prowadzi do innych konsekwencji i innych zobowiązań po stronie państw stron Paktu oraz innego katalogu kryteriów oceny, czy państwa dopuściły się naruszenia ciążących na nich zobowiązań, czy też nie. Nawet jeśli konsekwencje te i kryteria są w pewnym zakresie podobne, to jednak w sposób istotny różnią się. Mam tu na myśli przede wszystkim obowiązek poszanowania istoty praw i wolności zagwarantowanych w Pakcie oraz obowiązek realizacji minimalnej treści praw przez państwa. Obowiązków tych nie można uznać za tożsame. Pierwszy ma charakter absolutny, a drugi - względny.

Dotychczasowa aktywność Komitetu nie pozwala na precyzyjne zdefiniowanie wszystkich pojecć zawartych w art. 4 MPPGSK ani jego relacji do art. 2 ust. 1 MPPGSK. Brak precyzyjnej wykładni takich pojęć, jak istota/ natura praw, brak również precyzyjnej wykładni wymogu wprowadzania ograniczeń w celu popierania powszechnego dobrobytu w społeczeństwie demokratycznym. Szczególnie doprecyzowanie tego ostatniego wydaje się kluczowe, gdyż bez tego trudno będzie stwierdzić, czy do określonych działań państwa należy stosować art. 2 ust. 1 czy art. 4 MPPGSK. Dzięki analizie porównawczej, jak podobne pojęcia definiowane sa w innych reżimach ochrony praw człowieka, z wnioskami, z której aktywność Komitetu jest co do zasady spójna ${ }^{54}$, można jednak mieć pewne wyobrażenie, co do ich treści. Bardziej precyzyjne rozumienie art. 4 MPPGSK i wszystkich składających się nań elementów będzie mogło się dokonać wraz rozwojem aktywności KPGSK szczególnie w ramach procedury skargowej. Ważne jednak, ze względu na interes jednostki i wzmocnienie ochronnej funkcji Paktu, aby posłużyła ona dalszemu doprecyzowywaniu znaczenia poszczególnych jego postanowień, a nie doprowadziła do zacierania różnic wynikających z odmiennego charakteru zobowiązań, jakie nakłada on na państwa. Szczególnie ważne będzie w tym kontekście właściwe stosowanie art. 8 ust. 4 Protokołu fakultatywnego do MPPGSK, wprowadzajacego procedurę skargową.

Wtadysław Jóźwicki

Uniwersytet im. Adama Mickiewicza w Poznaniu

wjozwi@amu.edu.pl

https://orcid.org/0000-0002-0674-0814

${ }^{54}$ Por. np. Saul, Kinley, Mowbray (2014): 247-258. 
Alston, P., Quinn, G. (1987). The nature and scope of State Parties' under the International Covenant on Economic, Social and Cultural Rights. Human Rights Quarterly 9(2), 1987: 156-229.

Beiter, K.D. (2006), The Protection of the Right to Education by International Law, Leiden-Boston 2006.

Chenwi, L. (2009). Correcting the historical asymmetry between rights: the Optional Protocol to the International Covenant on Economic, Social and Cultural Rights. African Human Rights Law Journal 9(1): 23-51.

Coomans, F. (2002). In search of the core content of the right to education, [w:] A.R. Chapman, S. Russell (eds.), Core Obligations: Building a Framework for Economic, Social and Cultural Rights. Antwerp-Oxford-New York 2002: 159-182.

Coomans, F. (2004). Exploring the normative content of the right to education as a human right: recent approaches. Revista Persona y Derecho 50: 61-100.

Courtis, C. (2010). Commentary on the Optional Protocol to the International Covenant on Economic, Social and Cultural Rights, http://icj.wpengine.netdna-cdn.com/wp-content/ uploads/2009/07/Commentary-OP-ICESCR-publication-2009-eng.pdf [dostęp: 2.02.2018].

Craven, M.C.R. (1998). The International Covenant on Economic, Social, and Cultural Rights. A Perspective on Its Development. Oxford.

Garlicki, L. (2001). Przesłanki ograniczania konstytucyjnych praw i wolności (na tle orzecznictwa Trybunału Konstytucyjnego). Państwo i Prawo 54(10): 5-24.

Garlicki, L., Wojtyczek, K. (2016). Artykuł 31, [w:] L. Garlicki, M. Zubik (red.), Konstytucja Rzeczypospolitej Polskiej. Komentarz. Warszawa: 96-100.

Griffey, B. (2011). The 'reasonableness' test: assessing violations of state obligations under the Optional Protocol to the International Covenant on Economic, Social and Cultural Rights. Human Rights Law Review 11(2): 275-327.

Hauser, A. (2018). Protokół fakultatywny do Paktu, [w:] Z. Kędzia, A. Hernandez-Połczyńska (red.), Międzynarodowy Pakt Praw Gospodarczych, Socjalnych i Kulturalnych. Komentarz. Warszawa: 801-836.

Jayawickrama, N. (2002). The Judicial Application of Human Rights Law. National, Regional and International Jurisprudence. Cambridge.

Jóźwicki, W. (2018). Artykuł 4. Klauzula limitacyjna, [w:] Z. Kędzia, A. Hernandez-Połczyńska (red.), Międzynarodowy Pakt Praw Gospodarczych, Socjalnych i Kulturalnych. Komentarz. Warszawa: 186-214.

Kędzia, Z. (2014). Reinforcement of economic, social and cultural rights. European Yearbook on Human Rights 14: 23-37.

Kędzia, Z. (2018). Wprowadzenie do Międzynarodowego Paktu Praw Gospodarczych, Socjalnych i Kulturalnych, [w:] Z. Kędzia, A. Hernandez-Połczyńska (red.), Międzynarodowy Pakt Praw Gospodarczych, Socjalnych i Kulturalnych. Komentarz. Warszawa: 1-59.

Leckie, S. (1998). Another step towards indivisibility: identifying the key features of violations of economic, social and cultural rights. Human Right Quarterly 20(1): 81-124.

Mahon, C. (2008). Progress at the front: the Draft Optional Protocol to the International Covenant on Economic, Social and Cultural Rights. Human Rights Law Review 8(4): 617-646.

Müller, A. (2009). Limitations to and derogations from economic, social and cultural rights. $\mathrm{Hu}-$ man Rights Law Review 9(4): 557-601.

Nolan, A. (2014). Budget analysis and economic and social rights, [w:] E. Riedel, G. Giacca, C. Golay (eds.), Economic, Social, and Cultural Rights in International Law: Contemporary Issues and Challenges. Oxford: 369-390.

Saul, B., Kinley, D., Mowbray, J. (2014). The International Covenant on Economic, Social and Cultural Rights. Commentary, Cases Materials. Oxford.

Wojtyczek, K. (1999). Granice ingerencji ustawodawczej w sferę praw człowieka w Konstytucji RP. Warszawa.

Wróbel, A. (2013), Art. 52. [Zakres i wykładnia praw i zasad], [w:] A. Wróbel (red.), Karta Praw Podstawowych Unii Europejskiej. Komentarz. Warszawa: 1343-1384.

Young, K.G. (2008). The minimum core of economic and social rights: a concept in search of content. Yale Journal of International Law 33(1): 113-175. 


\title{
LIMITATIONS ON THE EXERCISE OF THE RIGHTS GUARANTEED BY \\ THE INTERNATIONAL COVENANT ON ECONOMIC, SOCIAL AND CULTURAL RIGHTS UNDER ARTICLE 4 THEREOF AND THE PROGRESSIVE EXERCISE OF THESE RIGHTS
}

\author{
Summary
}

Article 4 ICESCR is rarely applied or commented on. One of the most controversial issues regarding the understanding and application of this provision is its relation to the principle of the progressive exercise of rights covered by the Covenant. The key question comes down to whether or not any shortcomings in the possibility of exercising the rights contained in the Covenant, and thus also shortcomings related to the limited availability of resources and the resulting inability of the state to fully implement any of the rights or freedoms, should be understood as limitations and thus evaluated under Article 4 and the admissible criteria for limitations contained therein. The question becomes even more pertinent with regard to the introduction of so-called retrogressive measures, which are introduced by states when resources are limited. Should such measures be assessed under Article 4 ICESCR and the criteria stipulated therein, or do they fall under a different order and thus need to meet other conditions? This paper is an attempt at a delimitation of the issues associated with the lack of full enjoyment of Covenant rights by entitled persons due to limited resources, and as a result of other legitimate aims pursued by the States. The article shows how the justification of such a delimitation is based on travaux préparatoires, on the text of the Covenant itself, and on its protective function. In this paper, the way in which this delimitation can be made more precise by proper application of the communications procedure, especially when it comes to a proper understanding of Article 8(4) of the Optional Protocol, will be proposed.

Keywords: International Covenant on Economic, Social and Cultural Rights; ICESCR; Article 4; Article 2(1); limitation clause; limitations of economic, social and cultural rights; progressive realization of rights; retrogressive measures; Article 8(4) of the Optional Protocol to the ICESCR 